\title{
Calibration of the random settling technique for calculation of absolute abundances of calcareous nannoplankton
}

\author{
Markus Geisen ${ }^{1}$, Jörg Bollmann ${ }^{2}$, Jens O. Herrle ${ }^{3}$, Jörg Mutterlose ${ }^{4}$ and Jeremy R. Young ${ }^{1}$ \\ ${ }^{1}$ The Natural History Museum, Palaeontological Dept., London SW7 5BD, Great Britain \\ ${ }^{2}$ Eidgenössische Technische Hochschule, Geological Institute, Sonneggstr. 5, 8092 Zürich, Switzerland \\ ${ }^{3}$ Universität Tübingen, Institut und Museum für Geologie und Paläontologie, Sigwartstr. 10, 72076 Tübingen, Germany \\ ${ }^{4}$ Ruhr-Universität Bochum, Institut für Geologie, Universitätsstraße 150, 44801 Bochum, Germany \\ email: M.Geisen@nhm.ac.uk
}

\begin{abstract}
We describe a device for random settling preparation of calcareous nannoplankton (coccolith) samples. The device allows easy draining and cleaning, as well as sedimentation at different heights of the water column through the use of different slide carriers. Reproducibility and accuracy of the device has been tested with standardised microbeads as spiking material. In applying counting techniques with different equations for determining absolute abundances, we discovered major anomalies in the calculated results that we interpreted as being due to the effect of convection currents within the device and the usage of elevated cover slides. A modified formula that corrects for the influence of elevated cover slides in random settling experiments is therefore proposed. Although the settling method is more time-consuming than standard smear-slide techniques, additional information is gained about the spatial and temporal distribution of coccoliths. These are important for palaeoecological and palaeobiogeographical interpretations.
\end{abstract}

\section{INTRODUCTION}

The calculation of absolute abundances of coccoliths is valuable for comparison of spatial and temporal sample sets. Standard smear slide preparation techniques used for nannofossils do not provide this information since the quantity of sediment on the slide is not known. In recent years, various authors (Moore, 1973; Beaufort, 1991; Williams \& Bralower, 1995; Su, 1996; Flores \& Sierro, 1998; Baumann et al., 1999) have applied random settling techniques to allow the calculation of absolute abundances of coccoliths.

The basic principle of the random settling technique is that the nannofossils are allowed to settle out from a dilute suspension onto a cover slip. The abundance of the nannofossils can then be calculated from the weight of sediment put into suspension and the volume of the water column above the cover slip. Beaufort (1991), Williams \& Bralower (1995) and Su (1996) have described applications of this technique using standard laboratory equipment. We encountered problems in applying their methods due to dissolution of coccoliths during sedimentation, and an overall lack of precision in the design of the device used.

The initial objective of this study was to develop a convenient device in order to carry out random settling preparations and calculate absolute abundances of coccoliths (coccoliths per unit mass sediment). Design features of the device we developed, as described below, include a drain hole to allow removal of the water without evaporation, and cover slip holders designed to ensure convenient use and precise positioning. The advantage of the design described here is that it allows easy draining and cleaning. Additionally, the device allows preparations to be made at different heights in the water column. To test the reproducibility of results using this device repeat preparations were made of a single sample. In addition the accuracy of the calculated results was checked in two ways: First by using a sample for which absolute abundances had been calculated for another paper (Bollman et al., 1999); and second by spiking the sample with a known weight of borosilicate-glass microbeads.
This test produced rather surprising results. Since this is of significance for other applications of the random settling technique, the method is discussed in some detail here and the count data are presented in detail.

\section{MATERIAL}

\section{Random settling device}

The random settling device consists of an acrylic cylinder 80 $\mathrm{mm}$ high and $80 \mathrm{~mm}$ wide. It is fixed on an acrylic base, which is penetrated by a boring allowing the drainage of the water (Text-fig. 1, 2). An o-ring is used to seal the base. A fixed mark in the upper part of the cylinder allows precise control of the amount of water being used. A small hole in the centre of the base is used to fix the slide carriers. We used slide carriers of different heights to attain water columns, varying from 5 - 40 $\mathrm{mm}$ in $5 \mathrm{~mm}$ increments. Stainless steel is used for the clip on top of the slide carriers to avoid corrosion. The clip holds the cover slide in such a way that it is possible to remove the slide carriers without touching the cover slide.

\section{Spiking material}

As spiking material borosilicate microbeads with a mean diameter of $5.1 \mu \mathrm{m}$ (standard deviation $0.8 \mu \mathrm{m}$ ) and a specific gravity of $2.5 \mathrm{~g} / \mathrm{cm}^{3}$ have been used. The microbeads are produced by Duke Scientific, Product Number 9005, Lot No. 19324 (J. Bollmann, personal communication).

\section{Sediment samples}

In order to test the settling method we used the same sediment (fine fraction $<38 \mu \mathrm{m}$ of DSDP $607,2-2,29-32 \mathrm{~cm}$ ). This is a mid Pleistocene DSDP sample from the upper western flank of the Mid-Atlantic ridge, rouhgly 240 nautical miles northwest of the Azores (Ruddiman et al., 1987). The assemblage is dominated (>90\%) by G. oceanica.

For further tests whole rock samples from the middle Aptian of South-East France (Serre Chaitieu section, cf. Thierstein, 1973) have been used (PK74, PK84, PK85, PK86, PK87). 


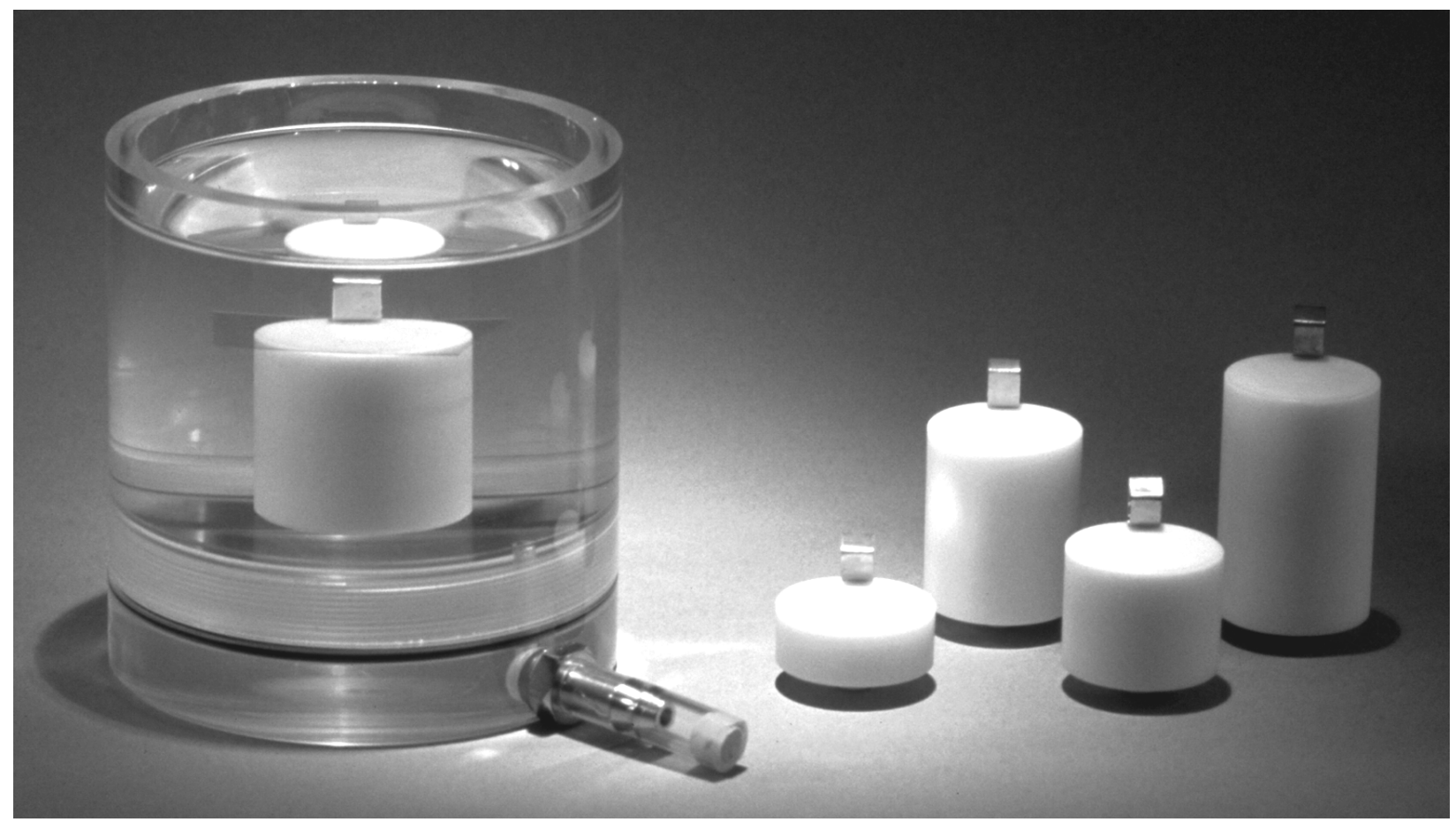

TEXT-FIGURE 1

Random settling device (left) and four slide carriers (right).The latter are used to attain different water column heights.

\section{Sample preparation}

1) A small amount of sediment is chopped off using a scalpel and dried in an oven for 24 hours at $50^{\circ} \mathrm{C}$. Alternatively the fine fraction of sieved and filtered samples $(<38 \mu \mathrm{m})$ can be used.

2) With bulk rock samples $10-50 \mathrm{mg}$ of sediment is weighed using a microbalance (Mettler AE 260 with a precision of $10^{-6} \mathrm{~g}$ ). The amount of material used depends on the coccolith abundance in each particular sample. With bulk rock samples this can usually be estimated by using the sediment colour as an indicator. With fine fraction samples $1-10 \mathrm{mg}$ of sediment is sufficient for both light- and scanning electron microscopy analyses. For control experiments $2-5 \mathrm{mg}$ of borosilicate microbeads are added to the sample.

3) The sample is transferred into a sealed tube. After adding a small amount of water, it is ultrasonicated until all particles are in suspension. We used normal tap water buffered with $\mathrm{NH}_{3}$ $(\mathrm{pH} \approx 8.5)$ to prevent etching and with a small amount of Triton $\mathrm{X} 100$ detergent added to remove surface tension.

4) The suspended sample is transferred to a volumetric flask and diluted to $1000 \mathrm{~cm}^{3}$. Afterwards the suspension is homogenised by a magnetic stirrer for several minutes followed by 4 inversions of the flask.

5) The suspension is poured into the settling device and left to settle for 24 hours. This settling time was based on the height of the water column. According to Stokes' Law (cf. Walsby \& Reynolds, 1980; Young, 1994) a $2 \mu \mathrm{m}$ diameter calcite sphere will sink at approximately $0.2 \mathrm{~mm} /$ minute, i.e. $300 \mathrm{~mm} /$ day. So 24 hours should ensure complete sedimentation of particles through the $50 \mathrm{~mm}$ water column.

6) The water is drained carefully using the drain valve. This procedure eliminates the need for evaporating the water and so reduces the preparation time to an acceptable minimum. Once the remaining water on the cover slide has air dried the slides are mounted in the usual way.

7) To avoid contamination of samples the device is cleaned thoroughly after each usage. Acids proved hard to remove entirely from the device and so were avoided.

\section{Counting}

When examining the slide under the light microscope or the scanning electron microscope the number of studied fields of view and the number of coccoliths in each field of view are noted. 600 fields of view per preparation were automatically captured at a magnification of 3000x using a scanning electron microscope (Philips XL30) and written on CD. Subsequently coccoliths were counted using a computer and the public domain image analysis program NIH-Image (developed at the U.S. National Institutes of health and available on the Internet at http:/ /rsb.info.nih.gov/nih-image/).

To gain comparable results only complete coccoliths and fragments of more than a half coccolith were counted, also Florisphaera profunda nannoliths were excluded in the SEM counts. The total number of coccoliths was calculated using the following equation (Williams \& Bralower, 1995):

$$
\mathrm{X}=(\mathrm{N} \times \mathrm{V}) /(\mathrm{M} \times \mathrm{F} \times \mathrm{A} \times \mathrm{H})
$$

where

$\mathrm{X}=$ particles per gram of sediment $[\mathrm{n} / \mathrm{g}]$

$\mathrm{N} \quad=\quad$ number of particles counted

$\mathrm{V}=\quad$ volume of water used for dilution [ml]

$\mathrm{M}=$ grams of sediment added $[\mathrm{g}]$

$\mathrm{F}=$ number of fields of view observed

$\mathrm{A}=\quad$ surface area of one field of view $\left[\mathrm{cm}^{2}\right]$

$\mathrm{H}=$ height of water column above slide $[\mathrm{cm}]$

This equation is based on the assumption that the number of 


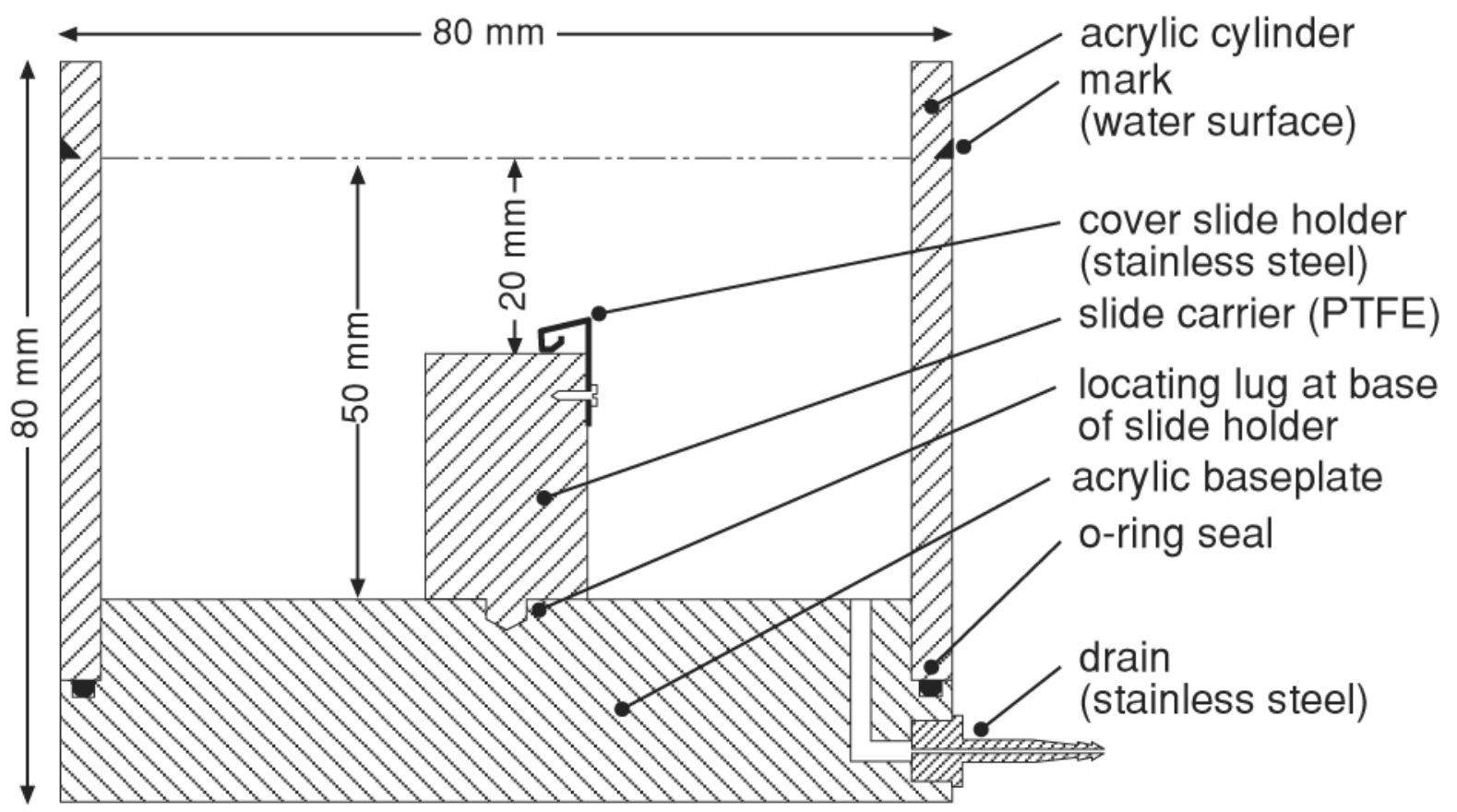

TEXT-FIGURE 2

Sketch of the random settling device used in this study.

particles, whether coccoliths or microbeads, collected per unit area of the cover slip is proportional to the volume of suspension originally present above the cover slip.

If the samples have been spiked by addition of a known number of microbeads then the total number of coccoliths can be calculated independently, by assuming that the relative abundance counts of the spheres and coccoliths are proportional to their absolute abundances. It is also necessary to calculate the number of microbeads per gram:

$X=6 \times 10^{12} /\left(\pi \times \rho \times d^{3}\right)$

where

$\begin{array}{lll}\mathrm{X} & = & \text { number microbeads } / \mathrm{gram} \\ \rho & = & \text { density of sphere }\left(\mathrm{g} / \mathrm{cm}^{3}\right) \\ \mathrm{d} & = & \text { mean diameter }(\mu \mathrm{m})\end{array}$

The calculated estimate is $5.76^{*} 10^{9}$ microbeads per gram. J. Bollmann (personal communication) used a lasergranulometer to determine independently the number of microbeads per gram. For these borosilicate microbeads a value of $5.86^{*} 10^{9}$ microbeads per gram is obtained. So it seems unlikely that there is a more than a couple of percent error in our calculated value.

Using the numbers estimated with equation 2 the number of coccoliths was now calculated as follows:

$$
\mathrm{X}=\left((\mathrm{N} / \mathrm{S}) \times\left(\mathrm{n}_{\mathrm{sph}} \times \mathrm{g}_{\mathrm{sph}}\right)\right) / \text { gsed }
$$

$$
\begin{array}{lll}
\text { where } & & \\
\mathrm{X} & = & \text { coccoliths per gram of sediment }[\mathrm{n} / \mathrm{g}] \\
\mathrm{g}_{\text {sph }} & = & \text { grams of spheres added }[\mathrm{g}] \\
\mathrm{g}_{\mathrm{sed}} & = & \text { grams of sediment added }[\mathrm{g}] \\
\mathrm{n}_{\mathrm{sph}} & = & \text { number of spheres } / \text { gram }(\text { see equation } 2) \\
\mathrm{S} & = & \text { number of microbeads counted } \\
\mathrm{N} & = & \text { number of coccoliths counted }
\end{array}
$$

\section{RESULTS}

The settling technique was tested by making 13 repeat preparations of the DSDP sample spiked with borosilicate microbeads. Depending $10^{10}$ on the density of the preparations 100 or 150 fields of view were counted, one of the preparations (76 \& 76a) was counted twice to show variation on one microscope stub (Text-fig. 3). Additionally five samples have been counted using a Zeiss photomicroscope at a magnification of $1600 \mathrm{X}$ to compare the scanning electron microscope counts with light microscope counts.

The average number of coccoliths calculated from the number of observed particles per area (equation 1) was $1.17 * 10^{11}$ coccoliths per gram with a coefficient of variation of $\pm 5.5 \%$ (Tab.1) for the scanning electron microscopy counts and $1.12 * 10^{11}$ coccoliths per gram with a coefficient of variation of $\pm 4.22 \%$ (Tab.1) for the light microscopy counts. The low variation in these results suggests they should be reliable. However, the average number of coccoliths calculated from the coccoliths to microbeads ratio (equation 2,3 ) was $4.59 * 10^{10}$ coccoliths per gram with a coefficient of variation of $\pm 16.2 \%$ (Tab. 1) for the scanning electron microscopy counts and $6.35^{*} 10^{10}$ coccoliths per gram with a coefficient of variation of $\pm 22.9 \%$ (Tab. 1) for the light microscopy counts. There are errors associated with counting both the coccoliths and the microbeads as well as errors in the calculation of the number of added microbeads. Hence the calculated abundance based on the ratio between coccoliths and microbeads inevitably contains larger, compound errors as reflected in the larger standard deviation. For the scanning electron microscope counts there is a fairly constant 2.54 times variation between these estimates, i.e. the calculated number of coccoliths based on the area equation is 2.54 times higher than the number of coccoliths obtained from the coccolith to microbead ratio, which was surprising (Tab. 1). Light microscope counts revealed a 1.82 times variation of these estimates which is explained by an apparent enrichment of microbeads in discrete areas of the slide and / or loss of microbeads during mounting with Canada balsam. 

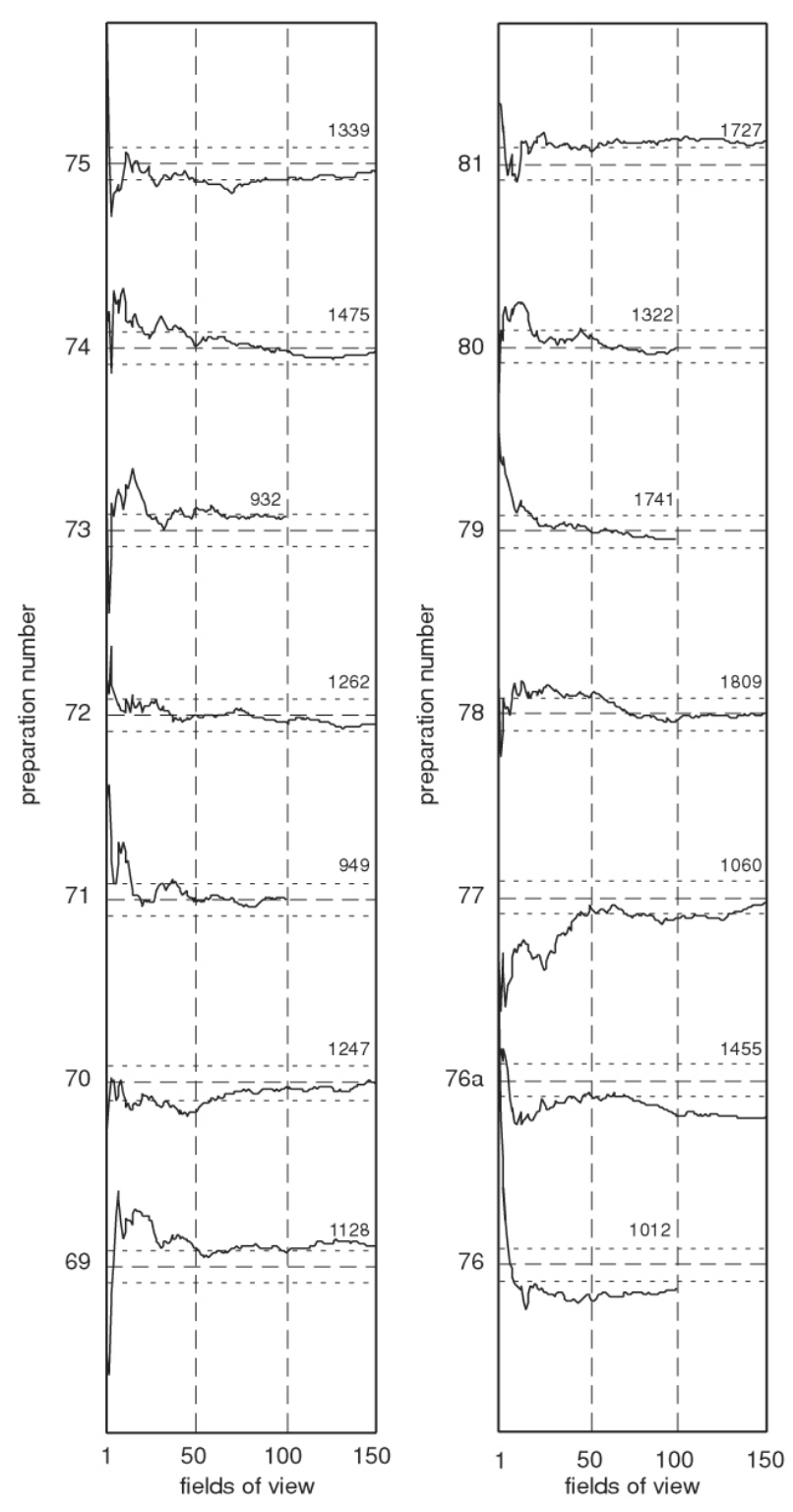

TEXT-FIGURE 3

Results for the SEM counts on repeated preparations of DSDP sample 607, 2-2, 29-32 cm. Each graph represents the evolution of the calculated number of coccoliths per gram. The broken lines represents the mean $\left(4.7 * 10^{10}\right)$ and standard deviation $\left(2.66 * 10^{9}\right)$ calculated from all 13 preparations using equation 1 $(\mathrm{H}=5 \mathrm{~cm})$. Note that samples 76 and $76 \mathrm{a}$ are double counts on different areas on the microscope slide. Numbers given in each graph are counted specimens. Counts stabilise after approximately 50 counted fields of view ( $\sim 500$ specimens); instability prior to this is due to the (low) unevenness in number of specimens per field of view. Variation in final values reflects the imprecision of the preparation method.

To investigate the anomaly, we first compared the known weight of the microbeads added to the samples, with the estimated weight from the microbeads counted. The estimated weight was approximately 2.5 times higher than the known weight (Tab.1, equation 2). We then compared our estimates of coccolith abundance in the sample with those calculated for the same sample in Bollmann et al. (1999). They estimate: 5.52*10 10 total coccoliths per gram (including $F$. profunda); $5.13 * 10^{10}$ (only Gephyrocapsa) and 5.3*10 $0^{10}$ coccoliths excluding F. profunda based on a spraying technique with a microbead spike; $4.27 * 10^{10}$ total coccoliths per gram based on a filtration technique, using a particles per area equation; and $4.9^{*} 10^{10}$ total coccoliths per gram based on a filtration technique with a microbead spike. Evidently our estimate of $4.59 * 10^{10}$ coccoliths per gram based on the microbead spike is much more comparable to those from other techniques. It follows that both the microbeads and the coccoliths are approximately 2.5 times more abundant on the cover slips than we would expect based on the independent estimates and the assumption of simple settling through the water column. Therefore we suspect that this enrichment is due to convection currents in the settling device. Close examination of settling suspensions did indeed reveal quite perceptible turbulent flow of particles in the suspension, continuing long after initial addition of the suspension. These flows were estimated by eye to have velocities in the order of $\mathrm{mm}$ per second. By contrast Stokes' Law sinking rates for coccoliths and microbeads should be orders of magnitude lower: $4 \mu \mathrm{m}$ per second, $0.2 \mathrm{~mm}$ per minute for a $2 \mu \mathrm{m}$ calcite sphere or $20 \mu \mathrm{m} /$ second, $1.4 \mathrm{~mm}$ per minute for a $5 \mu \mathrm{m}$ sphere. It is thus conceivable that the flows in the settling device cause prolonged random dispersion of the particles which the result of the particles settle out at similar rates on both the elevated cover slip and the base of the device. To test this assumption five bulk rock samples from the middle Aptian of South-East France have been prepared placing one slide on the bottom $(5 \mathrm{~cm})$ and the other one at $2 \mathrm{~cm}$ water column height. Afterwards the samples were counted with a light microscope to determine both the Assemblage composition and the number of coccoliths per gram. Neither the assemblages nor the total abundances show significant differences between the preparations (Tab. 2). Hence, the common assumption that the concentration of particles on the cover slip is proportional to height of the water column above the slip, is disproved. Indeed if we recalculate our results based on the total water column $(5 \mathrm{~cm})$ in the device, rather than the column above the cover slip the anomaly in our original data is removed (Tab. 1).

\section{CONCLUSIONS}

The results obtained with the commonly used particles per area equation (equation 1) to a high degree of precision are reproducible but yielded anomalous high values for the number of coccoliths per gram sediment. Using the microbeads as a tracer an enrichment of approximately 2.5 times for the settling device used could be demonstrated. We suspect that this apparent enrichment is due to convection currents in our new settling device. We suspect that convection currents occur in other settling set-ups although they might be influenced by room temperature, grain size and the geometry of the settling device.

These observations lead to the following conclusions:

(1) Our new settling device produces reproducible results, although (2) the commonly used particles per area equation yields incorrect results. (3) The settling technique and the particles per area equation remains a valid method if: the cover slide is placed on or near the bottom of the settling. Furthermore a microbead spike test can be carried out to check the results.

\section{ACKNOWLEDGEMENTS}

The authors appreciate the help of the mechanical workshop of the Ruhr-Universität Bochum, who built the random settling device. Prof. Hans Thierstein (Eidgenössische Technische Hochschule, Zürich) encouraged this work and kindly provided the DSDP sample, the microbeads and excellent SEM facilities as well as laboratory facilities. Dr. Steve Culver and Dr. Neale Monks carefully reviewed earlier versions of this manuscript. This work is a contribution of the EC-TMR research project CODENET. 
TABLE 1

Dataset showing the results for 13 repeated preparations of one sample (DSDP 607, 2-2, 29-32 cm) for scanning electron microscope (top) counts and light microscope counts (bottom). Field of view is $1.1631 * 10^{-5} \mathrm{~cm}^{2}$ for scanning electron microscopy observations and $1.13^{*} 10^{-4} \mathrm{~cm}^{2}$ for light microscopy observations. Note the great variation in the amount of sediment and microbeads put in the different preparations in contrast to the uniform results. Note that samples 76 and $76 \mathrm{a}$ are double counts on different areas on the microscope slide. H: height.

\begin{tabular}{|c|c|c|c|c|c|c|c|c|c|c|c|}
\hline \multicolumn{12}{|c|}{ SEM counts } \\
\hline$\frac{\frac{1}{0}}{\stackrel{0}{E}}$ & 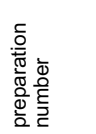 & $\begin{array}{l}\text { sediment } \\
\text { weight in } \\
\mathrm{mg}\end{array}$ & $\begin{array}{c}\text { spheres } \\
\text { weight in } \\
\text { mg }\end{array}$ & $\begin{array}{l}\text { fields of } \\
\text { view } \\
\text { counted }\end{array}$ & $\begin{array}{l}\text { coccoliths } \\
\text { counted }\end{array}$ & $\begin{array}{l}\text { beads } \\
\text { counted }\end{array}$ & $\begin{array}{l}\text { coccoliths per } \\
\text { gram fine } \\
\text { fraction (using } \\
\text { equation } 1 \text { with } \\
\mathrm{H}=2 \mathrm{~cm} \text { ) }\end{array}$ & $\begin{array}{l}\text { calculated weight } \\
\text { of spheres in } \\
\text { sample (using } \\
\text { equation } 1 \text { with } \\
\mathrm{H}=2 \mathrm{~cm} \text { ) in } \mathrm{mg}\end{array}$ & $\begin{array}{c}\text { ratio spheres } \\
\text { weight / spheres } \\
\text { calculated (using } \\
\text { equation 1with } \\
\mathrm{H}=2 \mathrm{~cm} \text { ) }\end{array}$ & $\begin{array}{l}\text { coccoliths per } \\
\text { gram fine } \\
\text { fraction } \\
\text { (equation 3) }\end{array}$ & $\begin{array}{l}\text { coccoliths per } \\
\text { gram fine } \\
\text { fraction (using } \\
\text { equation } 1 \text { with } \\
\mathrm{H}=5 \mathrm{~cm} \text { ) }\end{array}$ \\
\hline \multirow{14}{*}{ 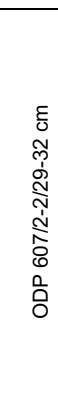 } & 69 & 2.635 & 3.551 & 150 & 1128 & 193 & $1.26 \mathrm{E}+11$ & 9.605 & 2.70 & $4.54 \mathrm{E}+10$ & $5.08 \mathrm{E}+10$ \\
\hline & 70 & 3.103 & 3.957 & 150 & 1247 & 187 & 1.17E+11 & 9.306 & 2.35 & $4.90 \mathrm{E}+10$ & $4.51 \mathrm{E}+10$ \\
\hline & 71 & 3.535 & 3.257 & 100 & 949 & 132 & $1.18 \mathrm{E}+11$ & 9.853 & 3.03 & $3.81 \mathrm{E}+10$ & $4.85 \mathrm{E}+10$ \\
\hline & 72 & 3.238 & 2.716 & 150 & 1262 & 161 & $1.14 \mathrm{E}+11$ & 8.012 & 2.95 & $3.79 \mathrm{E}+10$ & 4.70E+10 \\
\hline & 73 & 3.334 & 3.105 & 100 & 932 & 129 & $1.24 \mathrm{E}+11$ & 9.629 & 3.10 & $3.88 \mathrm{E}+10$ & $5.01 \mathrm{E}+10$ \\
\hline & 74 & 3.722 & 4.982 & 150 & 1475 & 254 & $1.16 \mathrm{E}+11$ & 12.640 & 2.54 & $4.48 \mathrm{E}+10$ & $4.80 \mathrm{E}+10$ \\
\hline & 75 & 3.424 & 3.927 & 150 & 1339 & 132 & $1.14 \mathrm{E}+11$ & 6.569 & 1.67 & $6.70 \mathrm{E}+10$ & $4.48 \mathrm{E}+10$ \\
\hline & 76 & 4.111 & 4.863 & 100 & 1012 & 155 & $1.08 \mathrm{E}+11$ & 11.570 & 2.38 & $4.45 \mathrm{E}+10$ & 4.37E+10 \\
\hline & $76 a$ & 4.111 & 4.863 & 150 & 1455 & 256 & $1.03 E+11$ & 12.740 & 2.62 & $3.87 \mathrm{E}+10$ & $4.29 \mathrm{E}+10$ \\
\hline & 77 & 2.715 & 3.723 & 150 & 1060 & 166 & $1.15 \mathrm{E}+11$ & 8.261 & 2.22 & $5.04 \mathrm{E}+10$ & $4.26 \mathrm{E}+10$ \\
\hline & 78 & 4.515 & 4.598 & 150 & 1809 & 219 & $1.18 \mathrm{E}+11$ & 10.898 & 2.37 & $4.84 \mathrm{E}+10$ & $4.82 \mathrm{E}+10$ \\
\hline & 79 & 6.758 & 3.909 & 100 & 1741 & 130 & 1.14E+11 & 9.704 & 2.48 & $4.46 \mathrm{E}+10$ & $4.82 \mathrm{E}+10$ \\
\hline & 80 & 5 & 3.154 & 100 & 1322 & 102 & 1.17E+11 & 7.614 & 2.41 & $4.71 \mathrm{E}+10$ & $4.83 \mathrm{E}+10$ \\
\hline & 81 & 3.946 & 3.125 & 150 & 1727 & 162 & $1.27 \mathrm{E}+11$ & 8.062 & 2.58 & $4.86 \mathrm{E}+10$ & $5.04 \mathrm{E}+10$ \\
\hline \multirow{3}{*}{\multicolumn{2}{|c|}{$\begin{array}{l}\text { mean } \\
\text { standard dev. } \\
\text { coefficient of variation }\end{array}$}} & & & & & & $1.17 \mathrm{E}+11$ & & 2.53 & $4.59 \mathrm{E}+10$ & $4.70 \mathrm{E}+10$ \\
\hline & & & & & & & $6.22 \mathrm{E}+09$ & & 0.35 & 7.46E+09 & $2.66 \mathrm{E}+09$ \\
\hline & & & & & & & $\pm 5.34 \%$ & & $\pm 16.2 \%$ & $\pm 16.2 \%$ & $\pm 5.66 \%$ \\
\hline
\end{tabular}

\begin{tabular}{|c|c|c|c|c|c|c|c|c|c|c|c|}
\hline \multicolumn{12}{|c|}{ LM counts } \\
\hline$\frac{\mathscr{\infty}}{\frac{0}{0}}$ & 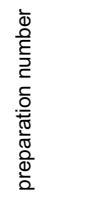 & $\begin{array}{l}\text { sediment } \\
\text { weight in } \\
\text { mg }\end{array}$ & $\begin{array}{l}\text { spheres } \\
\text { weight in } \\
\text { mg }\end{array}$ & $\begin{array}{l}\text { fields of } \\
\text { view } \\
\text { counted }\end{array}$ & $\begin{array}{l}\text { coccoliths } \\
\text { counted }\end{array}$ & $\begin{array}{l}\text { beads } \\
\text { counted }\end{array}$ & $\begin{array}{l}\text { coccoliths per } \\
\text { gram fine } \\
\text { fraction (using } \\
\text { equation } 1 \text { with } \\
\mathrm{H}=2 \mathrm{~cm} \text { ) }\end{array}$ & $\begin{array}{l}\text { calculated weight } \\
\text { of spheres in } \\
\text { sample (using } \\
\text { equation } 1 \text { with } \\
\mathrm{H}=2 \mathrm{~cm} \text { ) in } \mathrm{mg}\end{array}$ & $\begin{array}{c}\text { ratio spheres } \\
\text { weight / spheres } \\
\text { calculated (using } \\
\text { equation 1with } \\
\mathrm{H}=2 \mathrm{~cm} \text { ) }\end{array}$ & $\begin{array}{l}\text { coccoliths per } \\
\text { gram fine } \\
\text { fraction } \\
\text { (equation 3) }\end{array}$ & $\begin{array}{l}\text { coccoliths per } \\
\text { gram fine } \\
\text { fraction (using } \\
\text { equation } 1 \text { with } \\
\mathrm{H}=5 \mathrm{~cm} \text { ) }\end{array}$ \\
\hline \multirow{5}{*}{ 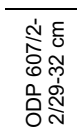 } & 69 & 2.635 & 3.551 & 9 & 640 & 59 & $1.19 \mathrm{E}+11$ & 5.032 & 1.42 & $8.42 \mathrm{E}+10$ & $4.77 \mathrm{E}+10$ \\
\hline & 70 & 3.103 & 3.957 & 9 & 719 & 81 & $1.14 \mathrm{E}+11$ & 6.909 & 1.75 & $6.52 \mathrm{E}+10$ & $4.55 \mathrm{E}+10$ \\
\hline & 71 & 3.535 & 3.257 & 9 & 804 & 62 & 1.12E+11 & 5.288 & 1.62 & $6.88 \mathrm{E}+10$ & 4.47E+10 \\
\hline & 72 & 3.238 & 2.716 & 9 & 692 & 68 & $1.05 \mathrm{E}+11$ & 5.715 & 2.10 & $4.92 \mathrm{E}+10$ & $4.20 \mathrm{E}+10$ \\
\hline & 78 & 4.515 & 4.598 & 9 & 1008 & 118 & 1.10E+11 & 10.065 & 2.19 & $5.01 \mathrm{E}+10$ & 4.39E+10 \\
\hline \multirow{3}{*}{\multicolumn{2}{|c|}{$\begin{array}{l}\text { mean } \\
\text { standard dev. } \\
\text { coefficient of variation }\end{array}$}} & & & & & & $1.12 \mathrm{E}+11$ & & 1.82 & $6.35 \mathrm{E}+10$ & $4.48 \mathrm{E}+10$ \\
\hline & & & & & & & $4.72 \mathrm{E}+09$ & & 0.29 & 1.45E+10 & $1.89 \mathrm{E}+09$ \\
\hline & & & & & & & $\pm 4.22 \%$ & & $\pm 16 \%$ & $\pm 22.9 \%$ & $\pm 4.22 \%$ \\
\hline
\end{tabular}

TABLE 2

Dataset showing the assemblage composition (in percent) and absolute abundances for five mid Aptian samples as determined with a light microscope. Field of view is $1.77 * 10^{-4} \mathrm{~cm}^{2}$. For each sample two preparations, one at $2 \mathrm{~cm}$ watercolumn and one at $5 \mathrm{~cm}$ watercolumn have been examined. Note the low variation in the two preparations of each sample in both the assemblage composition and the absolute abundances. The absolute abundances were calculated with equation 1 corrected for $5 \mathrm{~cm}$ water column.
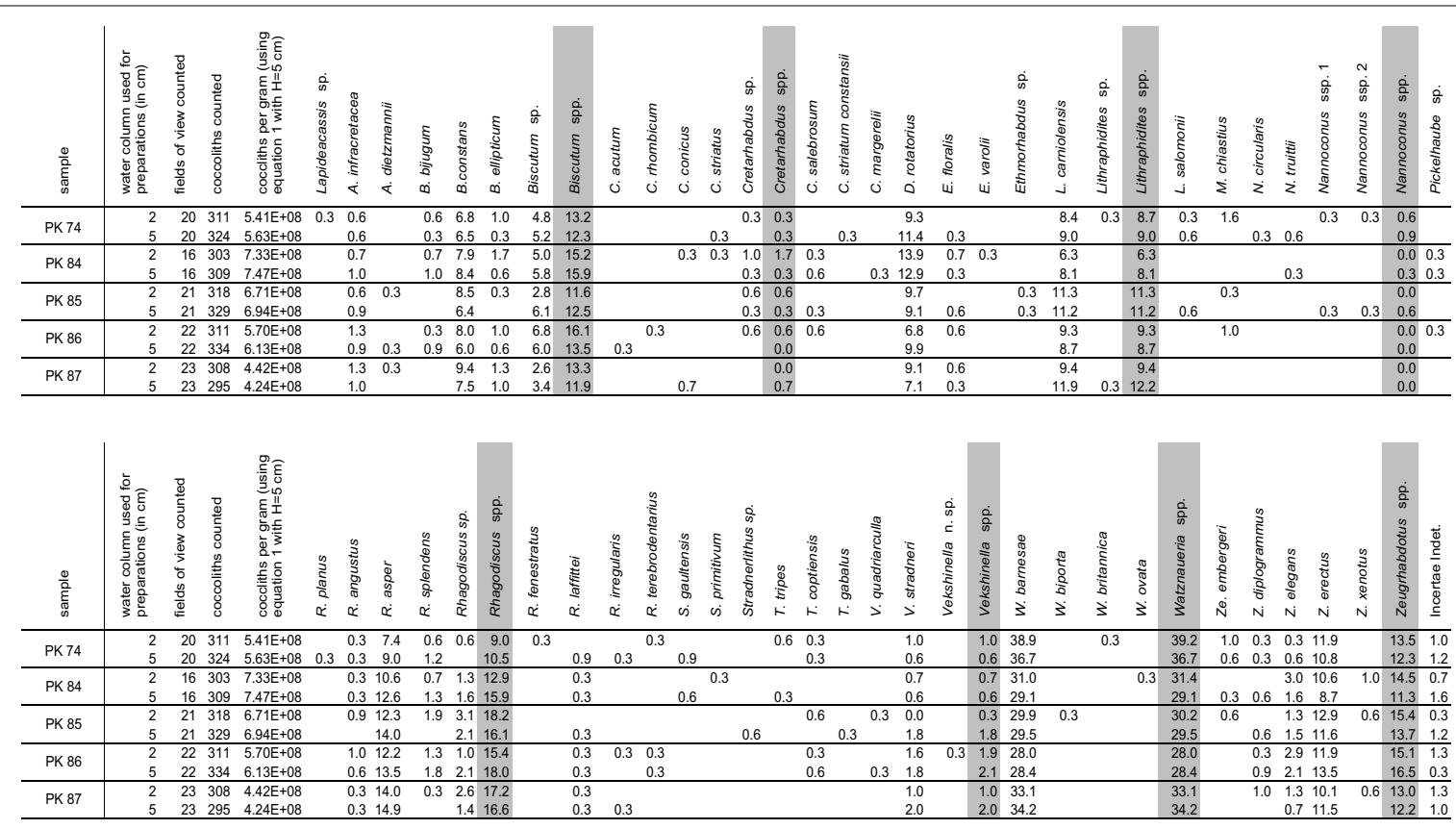

reproduced and amended from micropaleontology, vol. 45, no. 4, pp. 437-442, text-figures 1-3, tables 1-2, 1999 


\section{REFERENCES}

BAUMANN, K.-H., ANDRULEIT, A. H. and XIN SU, 1999. Comparison of different preparation techniques for quantitative nannofossil studies. Journal of Nannoplankton Research, 20 (2): 75-80.

BOLLMANN, J., BRABEC, B., CORTÉS, M. Y. and GEISEN, M., 1999. Determination of absolute coccolith abundances by spiking with microbeads and spraying (SMS-method). Marine Micropalaeontology, 38: 2938.

BEAUFORT, L., 1991. Adaptation of the Random settling method for quantitative studies of calcareous nannofossils. Micropaleontology, 37: 415-418.

FLORES, J.A., SIERRO, F.J., 1998. Revised technique for calculation of calcareous nannofossil accumulation rates. Micropaleontology, 43 (3): 321-324.

MOORE, T.C., 1973. Method of randomly distributing grains for microscopic examination. Journal of Sedimentary Petrology, 43 (3): 904-906.

RUDDIMAN, W.F., KIDD, R.B., THOMAS, E., et al., 1987. Initial Reports of the Deeps Sea Drilling Project. Volume 94, part 1: 1-613. Washington D.C.: U.S. Government Printing Office.
SU, X., 1996. Development of late Tertiary and Quaternary coccolith assemblages in the northeast Atlantic. Geomar Report, 48: 119 p.

THIERSTEIN, H.R. 1973. Lower Cretaceous calcareous nannoplankton biostratigraphy. Abhandlungen der Geologischen Bundundesanstalt, 29: $52 \mathrm{p}$.

WALSBY, A.E., REYNOLDS, C.S. 1980. Chapter 10. Sinking and floating. In: Morris, I. (Editor), The Physiological Ecology of Phytoplankton. Studies in Ecology, 7: 371412.

WILLIAMS, J.R., BRALOWER, T.J., 1995. Nannofossil assemblages, fine fraction stable isotopes, and the paleoceanography of the Valanginian-Barremian (Early Cretaceous) North Sea Basin. Paleoceanography, 10 (4): 815-839.

YOUNG, J.R. (1994). Functions of coccoliths. In: Winter, A. and Siesser, W.G. (Editors), Coccolithophores, pp. 6382. Cambridge: Cambridge University Press.

Manuscript received December 30, 1998

Manuscript accepted April 15, 1999 